\title{
AMIZADE E MEMÓRIA: MARIA ISAURA PEREIRA DE QUEIROZ E ROGER BASTIDE*
}

\author{
Glaucia Villas Bôas
}

Depois da morte de Roger Bastide, em 1974, Maria Isaura Pereira de Queiroz se envolveu com a memória do amigo, tomando diversas iniciativas com o objetivo de recuperar e divulgar a obra do mestre francês que havia voltado ao seu país duas décadas antes. Entre as iniciativas, ela compilou, com a ajuda de Charles Beylier ${ }^{1}$, os artigos de autoria de Bastide dispersos em inúmeros periódicos e jornais; elaborou um projeto de publicação das obras completas do seu ex-professor, organizou dois seminários, escreveu textos sobre a obra de Bastide e prefaciou livros, publicados postumamente na França. Os esforços empreendidos por Maria Isaura para preservar o legado de Roger Bastide estão registrados na correspondência à viúva, Jeanne Bastide, e

\footnotetext{
* Sou grata a Monica Pimenta Velloso, Ana Paula Simioni, Claudia de Oliveira e Joëlle Rouchou pelo convite para participar do Seminário Criações Compartilhadas, em novembro de 2012, que motivou a escrita deste texto.

${ }^{1}$ Charles Beylier, assistente de Henri Desroche, reunia, no Brasil, em meados da década de 1970, a bibliografia de Bastide, que utilizou na sua tese de doutorado L'Oeuvre brésilienne de Roger Bastide (1898-1974), de 1977, e na organização do acervo do Arquivo Roger Bastide do Instituto de Estudos Brasileiros da Universidade de São Paulo.
} 
sua filha Suzanne, entre 1975 e $1989^{2}$. As cartas exprimem tal empenho para evitar o esquecimento de Bastide, tanto na França como no Brasil, que levam a pensar no significado da relação de parceria e amizade havida entre os dois sociólogos por mais de trinta anos.

Na trama da relação entre Maria Isaura e Roger Bastide, podem-se apreciar dois momentos distintos, ocorridos antes e depois de sua morte: o primeiro define-se pela presença do professor na formação de Maria Isaura e também pela parceria dos dois enquanto colegas; o segundo diz respeito ao projeto de construção da memória de Bastide acalentado por Maria Isaura. No primeiro caso, a convivência se faz entre professor e aluna e entre cientistas sociais e autores. No segundo, o da construção da memória, o papel de Maria Isaura relembra aquele das filhas apaixonadas ou esposas amantes que escrevem sobre os pais ou maridos. Günther Roth (1995, p. 13) cunha os termos "filhas apaixonadas e 54 esposas amantes" na introdução à biografia de Max Weber escrita por sua esposa, Marianne Weber, mas, ao contrário do que se possa imaginar, Roth sai na defesa intransigente de Marianne Weber e das mulheres que, na Alemanha do início do século XX, preservaram a memória dos pais ou maridos. Sem elas, diz ele, muitos intelectuais não teriam reconhecimento. Considero, entretanto, as categorias de Roth pouco adequadas à compreensão da posição de Maria Isaura.

Pode-se também atribuir o interesse pela construção da memória do amigo a um cálculo de Maria Isaura. O desejo de manter viva a memória de seu professor teria como motivo qualificar sua própria posição no campo das ciências sociais, e não as qualidades intrínsecas da obra de Bastide. Contudo, nos dezesseis anos em que esteve no Brasil

\footnotetext{
${ }^{2}$ Essa correspondência está depositada no Imec (Institut de la Mémoire de l'Edition Contemporaine), em Caen, França. Agradeço a Aline Marinho a gentileza de me ceder trechos das cartas referidas.
} 
(1938-1954), Roger Bastide foi professor de jovens que se tornaram intelectuais e cientistas sociais de renome, como Mário Wagner Vieira da Cunha, Florestan Fernandes, Antonio Candido de Mello e Souza, Gilda Rocha de Mello e Souza, Gioconda Mussolini, Egon Schaden, Lucila Hermann, Lourival Gomes Machado, Ruy Coelho, Azis Simão, Duglas Teixeira Monteiro, Fernando Henrique Cardoso, Octavio Ianni, Marialice Mencarini Foracchi e Maria Sylvia Carvalho Franco. Na França, na década de 1970, orientou a tese de doutorado de Renato Ortiz. Maria Isaura, por sua vez, mantinha um círculo de amigos e parceiros de trabalho no qual se destacavam os franceses Fernand Braudel, Lucien Febvre, Charles Morazé, Pierre Monbeig, Paul Arbousse Bastide e Georges Balandier, que conhecera em São Paulo ou em Paris, em meados dos anos de 1950, quando fazia seu doutorado com bolsa do governo francês. A referência aos brasileiros, alunos e amigos de Bastide, assim como a menção aos franceses, amigos e parceiros de trabalho de Maria Isaura, servem aqui apenas para evidenciar que os motivos do projeto de construção da memória de Roger Bastide por Maria Isaura não se deixam explicar tão facilmente: Maria Isaura poderia ter escolhido outro mestre francês para dedicar seu projeto de memória, assim como Bastide poderia ter sido "escolhido" por outros alunos e amigos brasileiros.

Sabe-se, no entanto, que Maria Isaura, bem mais do que outros colegas, amigos e alunos de Bastide, manteve uma relação de proximidade e parceria com o mestre na cidade de Paris, onde ela exerceu atividades profissionais, ministrando cursos, fazendo palestras e pesquisas, e publicando livros e artigos de sua autoria por mais de trinta anos. A ligação intensa e regular de Maria Isaura com sociólogos e historiadores franceses, incluindo a duração prolongada do convívio com Bastide, distingue a sua posição daquela de seus colegas e contemporâneos, e pode pesar em favor de sua determinação na construção da memória do mestre. Doutro modo, 
leve-se em conta, na escolha de Maria Isaura, o fato de que, entre os seus professores e colegas franceses, foi, sem dúvida, Bastide aquele que se dedicou mais intensa e prolongadamente à pesquisa e escrita sobre o Brasil, deixando uma obra importante sobre a cultura e a sociedade brasileira (cf. Peixoto, 2000). Esses fatos contribuem para o entendimento da escolha de Maria Isaura, mas não excluem a possibilidade de haver um cálculo no empreendimento da socióloga. Não é possível, porém, trabalhar com essa hipótese nos limites deste texto. Suspendo, por isso, provisoriamente, a suspeita de que os esforços de Maria Isaura visariam à consagração do seu professor com o intuito de legitimar sua própria posição e obra no campo das ciências sociais.

Ao "descartar" tanto a paixão como o cálculo que, supostamente, motivam e se inscrevem em projetos de memória, limito-me aqui a fazer algumas anotações sobre a convivência de Maria Isaura com Roger Bastide. Ao longo 56 do tempo, as relações entre eles se apresentam simétricas e assimétricas, iguais e desiguais. Enquanto intelectuais e pesquisadores no campo das ciências humanas, pode-se pensar em igualdade de condições e simetria; em assimetria e desigualdade, ao levar-se em conta o lugar de Maria Isaura enquanto ex-aluna e mulher. A amizade dos dois é vivida nas cidades de São Paulo e Paris. Estrangeiro no Brasil, Roger Bastide se entusiasma pelo conhecimento de um país tão diferente do seu, enquanto acolhe Maria Isaura, por muitos anos, em projetos profissionais de divulgação da sociologia e da pesquisa sobre o Brasil em Paris. Chama a atenção a raridade dessa parceria que persiste na distância por muitos anos. Mas ela é mais notável ainda pelo fato de que, na época, pouquíssimas mulheres alcançaram autonomia intelectual como Maria Isaura, ou a psiquiatra Nise da Silveira, mas eram muitas delas uma espécie de "garante" do sucesso dos homens, em geral pais ou maridos, a exemplo de Mary Houston, esposa do crítico de arte Mario Pedrosa. 
Finalmente, desejo enfatizar que, nessa reflexão sobre a amizade e o coleguismo de Maria Isaura e Roger Bastide, não procuro rastrear a recepção de ideias, hipóteses e resultados de trabalho de campo - de autoria de Maria Isaura - na obra de Bastide. Mostro apenas que, apesar de não seguir as orientações metodológicas de seu professor, há, entre eles, interesse numa mesma temática de pesquisa e um compromisso de Maria Isaura na construção da memória do amigo após sua morte. O ideal em uma pesquisa sobre "criações compartilhadas" seria consultar a vida e obra de Bastide e confrontar com a de Maria Isaura para verificar se ele teria dialogado com as ideias e hipóteses de sua ex-aluna. Tal atitude seria, sem dúvida, mais cautelosa, a julgar os efeitos das trocas recíprocas que definem as interações humanas, como mostra Simmel (cf. Moraes Filho, 1993) com maestria. Essa comunicação constitui-se, entretanto, em exercício inicial e precário, cujo objetivo é apontar questões sobre a memória no campo das ciências sociais.

Inicialmente se delineará um breve perfil dos dois sociólogos; depois se abordará a parceria intelectual, apontando conceitos e categorias inscritos na obra de Maria Isaura que relembram posições tomadas por Roger Bastide em suas análises da cultura brasileira, assim como sublinha temas e posições analíticas dele que não foram acatados por Maria Isaura; e, por fim, apresentará dados sobre o projeto de construção da memória de Roger Bastide no Brasil.

\section{Roger Bastide e Maria Isaura}

Roger Bastide e Maria Isaura conheceram-se na Universidade de São Paulo (USP), onde ela era aluna e tornou-se assistente do mestre francês. Era vinte anos mais jovem que seu professor. Bastide chegou ao Brasil, com quarenta anos, em 1938, para ocupar a cátedra de Sociologia I, no Departamento de Ciências Sociais dessa universidade, deixada vaga 
pelo professor Claude Lévi-Strauss ${ }^{3}$. Em 1954, voltou definitivamente para a França, onde foi lecionar na École Pratique des Hautes Études, 6e. Section, hoje École des Hautes Études en Sciences Sociales (Escola de Estudos Avançados em Ciências Sociais); nomeado em seguida para a Universidade de Paris, cátedra de Sociologia, exerceu a docência também, durante mais de dez anos, no Institut des Hautes Études de L'Amérique Latine (Instituto de Estudos Avançados da América Latina).

Roger Bastide nasceu em Nîmes, na França, em 1898, em uma família de professores. Viveu em Anduze, nas Cévennes. Segundo Maria Isaura Pereira de Queiroz (1983, p. 7), "desde criança, viu-se mergulhado nas contradições socioculturais que constituíram, pela sua vida afora, o pano de fundo de suas pesquisas [...] pertencia a uma minoria religiosa num país de maioria católica; e na paisagem que o rodeava encontrava ao mesmo tempo o forte colorido mediterrâneo, aliado às severas montanhas e florestas de Cévennes".

Após o término do Liceu em Nîmes, em 1915, sua formação foi marcada pela Primeira Guerra e o serviço militar. Na Universidade de Bordeaux, obteve o Diplôme de Études Superieures em filosofia e, em 1924, a agrégation em filosofia, que lhe permitiu ensinar em diferentes liceus. O jovem Bastide exerceu atividades docentes, políticas e literárias. Em Diálogos brasileiros: uma análise da obra de Roger Bastide, Fernanda Peixoto examina com sutileza os escritos de Bastide, publicados na França antes de sua vinda ao Brasil, suas relações com o campo intelectual francês e seus projetos. Conclui que "entrar em contato com sua produção [a de Bastide] dos anos 20 e 30 significa enveredar pelos domínios da poesia, da vida mística e da religião" (Peixoto, 2000, p. 23). Nos dezesseis anos em que permaneceu no Brasil, as marcas iniciais da vida e formação de Bastide são alteradas,

\footnotetext{
${ }^{3}$ Sobre as relações entre Bastide e Lévi-Strauss, ver Braga (2009).
} 
ampliando-se o leque de temas de seu interesse, a exemplo do folclore e das relações raciais, das religiões afro-brasileiras e da modernização do país, bem como o enfoque de tais temas a partir de contribuições da sociologia e antropologia de autores estrangeiros, reelaboradas pelo pesquisador, mas também pelo diálogo interessado com os intérpretes e pesquisadores brasileiros ${ }^{4}$. Os anos da estada de Bastide no país foram de grande efervescência intelectual, especialmente na cidade de São Paulo, que se transformava rapidamente e via crescer sua jovem universidade.

Roger Bastide voltou duas vezes ao Brasil. Em 1962, permaneceu mais tempo na cidade, a convite da Universidade de São Paulo. Mas, em 1973, ficou apenas de julho a setembro, "entregando-se", segundo Maria Isaura,

[...] com entusiasmo juvenil à tarefa que se propusera executar: verificar o que se passava na Amazônia, no que diz respeito a interpenetrações de civilizações, pois não estudara ainda diretamente o problema naquela área; verificar em $\mathrm{S}$. Paulo se as hipóteses que havia formulado 20 anos antes, para o desenvolvimento das relações entre pretos e brancos numa cidade em processo veloz de industrialização, estavam ou não se verificando; e, finalmente, rever por toda parte, no Rio de Janeiro, em Salvador, em São Paulo, os muitos amigos que aqui havia deixado, entre os intelectuais, nos candomblés e nos terreiros, nos clubes e sociedades culturais negras - tanto mais que o tempo ia abrindo constantemente entre eles claros irreparáveis (Pereira de Queiroz, 1976c, p. 51).

No ano seguinte a essa viagem, Roger Bastide faleceu em Paris, em abril de 1974. Maria Isaura esteve presente na cerimônia fúnebre que antecedeu o enterro e na qual

\footnotetext{
${ }^{4}$ Um dado importante da vida de Roger Bastide no Brasil foi sua iniciação no candomblé. A esse respeito, ver Pereira de Queiroz (1983, pp. 13-21) e Fry (1986, pp. 31-45).
} 
soaram os tambores de culto, o toque brasileiro alternando o toque africano em homenagem ao filho de xangô, protestante convicto, que deixava este mundo.

Maria Isaura nasceu em 26 de agosto de 1918, na cidade de São Paulo, filha de Manoel Elpídio e Maria Pereira de Queiroz. Seus antepassados paternos cultivavam café em propriedades próximas ao Rio Paraíba do Sul, e os de sua mãe se ocuparam com a plantação de café no oeste paulista. Oriunda de uma família quatrocentona com doze filhos, viveu e acompanhou as profundas transformações sociais, econômicas e políticas que ocorreram no país, sobretudo no estado de São Paulo. Tais mudanças afetaram a posição e os bens de sua família, porém não impediram o cultivo dos hábitos refinados, da boa cultura e educação, nem a manutenção de laços de amizade e relações próximas com indivíduos investidos de posição de mando e prestígio na sociedade paulista.

Em dedicatória do livro Cultura, sociedade rural e socieda60 de urbana no Brasil, Maria Isaura Pereira de Queiroz (1978) escreve que o mundo ao qual ela e os irmãos pertenciam tinha perdido todas as suas bases materiais. É importante assinalar também que, em contraste com o refinamento do seu círculo familiar, a jovem Maria Isaura fez sua formação em escolas e colégios da rede pública paulista, onde conviveu mais de quinze anos com colegas de origem social e econômica muito diversa da sua, preparando-se para o magistério no curso normal. O conhecimento de um mundo fora dos limites de sua classe social possivelmente deixou marcas em sua biografia. Anos mais tarde, ao receber o título de professora emérita da USP, ela lembrou-se de sua experiência na escola, cuja importância se resumia na constatação de que "inteligência, aptidões e dotes de coração não dependem de forma alguma da maior quantidade de bens de fortuna" (Pereira de Queiroz, 1990, p. 20).

Ao terminar sua formação na USP, onde estudara com professores brasileiros e franceses, destacando-se entre 
eles Roger Bastide, Maria Isaura viajou, em 1951, para Paris com uma bolsa do governo francês. Em cinco anos, obteve o diploma da Escola Prática de Estudos Avançados (École Pratique des Hautes Études - Ephe), com a tese Guerra Santa no Brasil: o movimento messiânico do Contestado, orientada por Roger Bastide (Pereira de Queiroz, 1957). Tornou-se professora da USP, ocupando o cargo de assistente da cadeira de Sociologia I, de 1951 a 1958, e como assistente-doutor da Cadeira de Sociologia II, de 1958 a 1963. Permaneceu como docente e pesquisadora dessa universidade até 1990. Além da atividade intensa na USP, ao término de seus estudos em Paris, Maria Isaura integrou-se aos circuitos sociológicos parisienses, dirigindo e participando de seminários, ministrando disciplinas com base em suas pesquisas e publicando artigos e livros ${ }^{5}$.

O campo sociológico francês se reestruturava, enfrentando, de início, dois adversários: o partido comunista francês e a filosofia que dominava os meios intelectuais franceses e, logo depois, as pelejas provocadas pelo estruturalismo. Georges Gurvitch, Georges Balandier, Jean Duvignaud e Alain Touraine se empenharam no desenvolvimento de um instrumental teórico que fizesse face ao modelo estruturalista, sublinhando a necessidade de focalizar as experiências das mudanças sociais e históricas. Durante mais de trinta anos, Maria Isaura participou ativamente das atividades desse grupo. A convite de Georges Gurvitch, Fernand Braudel, Pierre Monbeig, Henri Desroche, Viola e Ignacy Sachs, ela ministrou cursos e dirigiu seminários na Ephe, no Instituto de Estudos Avançados da América Latina e na Escola de Estudos Avançados em Ciências Sociais, posicionando-se, assim como seus colegas, contra a corrente estruturalista e os enfoques filosóficos e destacando a relevância da sociologia empírica e histórica.

${ }^{5}$ Sobre a trajetória de Maria Isaura em Paris, ver Lopes (2012, pp. 31-37). 
Contudo, a formação de Maria Isaura e a construção de suas hipóteses de trabalho não poderiam ser compreendidas sem a atenção devida às viagens que fez a Santa Brígida, velho povoado do município de Jeremoabo, terra de Maria Bonita, na divisa dos estados da Bahia e Alagoas. Jeremoabo, descrito por Euclides da Cunha em Os sertões, era lugarejo pobre, habitado por sertanejos que guardavam ainda intactas as tradições do passado. A relação do trabalho de Maria Isaura em Santa Brígida com sua perspectiva teórica possibilita avaliar de que modo ela busca superar a dicotomia estrutura versus ação, articulando as chamadas dimensões "micro" e "macro" da vida social e construindo um caminho próprio para o entendimento das mudanças sociais (Botelho e Carvalho, 2011). Além da inegável importância do trabalho de campo na constituição da obra da socióloga, podem-se imaginar as vivências diferenciadas de uma jovem que se deslocava regularmente da cidade de São Paulo para Paris, de 62 Paris para Santa Brígida, de Santa Brígida para São Paulo. Certamente não era um trajeto comum para os cientistas sociais daquela época, sobretudo para as poucas mulheres que haviam se formado nos cursos de ciências sociais ${ }^{6}$.

\section{Diálogo e criação intelectual}

Maria Isaura optou pelo estudo das coletividades pobres e dominadas com um interesse eminentemente político. No elenco dos sociólogos dos anos de 1950 e 1960, ela era um espécime raro a estudar a mudança social do ponto de vista das populações rurais, de sua cultura, de sua religião e de seus movimentos messiânicos, com o intuito de averiguar sua capacidade política. Argumentei em outros artigos (Villas Bôas, 2009, 2010) que as escolhas temáticas de Maria Isaura não devem ser explicadas limitadamente pelo fato de

\footnotetext{
${ }^{6}$ Thales de Azevedo, catedrático de antropologia e etnografia da Faculdade de Filosofia da Universidade da Bahia, incentivou e apoiou as atividades de Maria Isaura naquele estado nos anos de 1954 a 1958.
} 
ser uma mulher nascida em família quatrocentona paulista. Suas escolhas são próprias de uma tradição de estudos da cultura brasileira, que inclui o cangaço, a vida de Maria Bonita e Lampião, o Bumba meu Boi, a Dança de São Gonçalo, entre outros temas presentes tanto nas ciências sociais como na cinematografia brasileira, na literatura, nas artes plásticas e na recente produção televisiva de novelas. A escolha de temas da cultura brasileira não obscureceu o interesse político de seus estudos, mas foi, ao contrário, a porta de entrada de suas pesquisas na área da sociologia política.

Sua obra está pautada pela hipótese ousada e controvertida de que os grupos subalternos são capazes de organizar e liderar movimentos em favor da melhoria de suas condições de vida. O messianismo no Brasil e no mundo, livro que publicou em 1965, talvez seja o melhor exemplo de sua escolha (Pereira de Queiroz, 1976b). Ao apostar naquela hipótese, a autora inverte a crença comum de que os despossuídos de bens são incapazes de ação em benefício próprio, uma vez que se acredita que estejam naturalmente presos ao imobilismo, à espera de um movimento que os retire das duras condições em que vivem, iluminando suas mentes. Diga-se que os estudos de Maria Isaura sobre a mudança social não ficaram circunscritos aos grupos destituídos de bens materiais e poder de mando. Questionou o sistema político brasileiro do ponto de vista dos poderosos mandões locais. No entanto, mesmo nas pesquisas que compõem o livro $O$ mandonismo local na vida política brasileira e outros ensaios (Pereira de Queiroz, 1976a), o leitor percebe que, para a autora, os grupos e indivíduos dominados, sujeitos ao poder de mando, tinham capacidade de discernimento e, no limite, sabiam das condições estreitas de suas escolhas. Argumentou contra a existência do "voto de cabresto", afirmando que, nas sociedades de parentela, o voto fazia parte de um sistema complexo de reciprocidades (Pereira de Queiroz, 1976a, p. 17). 
Pode-se arriscar dizer então que, se os temas de Maria Isaura são conservadores e pertencentes a uma tradição de pensamento voltada para a "cultura brasileira", não o são suas hipóteses e questões de trabalho. A mudança social foi raramente abordada do ponto de vista das relações entre os que exercem o poder de mando e aqueles que se submetem a ele, e, mais raramente ainda, a pesquisa da mudança social foi pautada por uma hipótese - tão contrária às diretrizes de meados do século XX - e que confere capacidade de discernimento aos pobres e destituídos de bens materiais e intelectuais.

Sob uma aparente simplicidade discursiva, o pensamento de Maria Isaura não se deixa revelar tão facilmente assim, sendo importante para sua leitura o entendimento de noções que coerentemente fundamentam sua obra. Elas dizem respeito: (1) à recusa do etnocentrismo no processo de investigação; (2) a uma concepção de his64 tória singular; e (3) a uma noção de mudança social que inclui a conservação e a permanência, assim como a reforma ou a revolução. Seria possível estabelecer um diálogo entre a obra de Maria Isaura e a de Roger Bastide a partir dessas noções? Há convergências no pensamento dos dois autores, ou simplesmente discordâncias? Indico aqui três questões que não esgotam nem de longe a complexidade do assunto, mas podem ser desenvolvidas em estudos posteriores.

Considero a retomada da tradição do pensamento brasileiro anterior à institucionalização das ciências sociais um primeiro ponto compartilhado entre os dois cientistas sociais. A importância das leituras de Euclides da Cunha, Manoel Querino e Nina Rodrigues, Silvio Romero, Gilberto Freyre, Mario de Andrade e Oliveira Vianna pode ser observada no processo de formulação de hipóteses e escolha de temas de investigação que distinguem tanto a obra de Maria Isaura como a de Roger Bastide. Não se tratava, 
pois, de leitura que visasse apenas conhecer as ideias dos "precursores das ciências sociais", como chamava Maria Isaura (Pereira de Queiroz, 1979), mas de leitura que servisse de ponto de partida para novos projetos de pesquisa. A releitura de pensadores/intérpretes do Brasil - no sentido explícito de reformular suas hipóteses de trabalho - não era comum na época em que Bastide aqui viveu, sendo essa atividade intelectual relegada ao segundo plano para que novos atores da sociologia e antropologia francesa e norte-americana, assim como da sociologia alemã, fornecessem os instrumentos conceituais e teóricos para a elaboração de hipóteses e, assim, contribuíssem para legitimar um conhecimento de natureza científica.

Em suas pesquisas brasileiras, como mostram os intérpretes, Bastide concebe uma problemática central que não mais abandonará - a dos contatos culturais. Mas o que é fundamental, e muito pouco discutido, é que durante a estada brasileira, Bastide forja um ponto de vista teórico e metodológico particular, dissonante dos padrões de seu tempo (Peixoto, 2000, p. 16).

Além das tradições sociológicas e antropológicas francesa e norte-americana, diz Peixoto (2000, p. 16) que, no Brasil, Bastide entra em contato "de modo particular (com) as linhagens intelectuais nacionais que ocupam lugar destacado na obra do autor". Nessa retomada da tradição de pensamento, Bastide dialogou, particularmente, com Mario de Andrade, Gilberto Freyre e Florestan Fernandes (cf. Peixoto, 2000). Aparentemente, Maria Isaura não teve preferências iguais. A julgar por suas pesquisas, a dívida maior foi com Euclides da Cunha, cuja presença se faz sentir não apenas no tema dos movimentos messiânicos, mas também nos seus trabalhos sobre o campesinato (Pereira de Queiroz, 1973), nos quais a autora discorda das hipóteses de Euclides sobre 
o isolamento dos habitantes do mundo rural e seus efeitos perversos, com o intuito de perseguir novas questões ${ }^{7}$.

A retomada da tradição desdobra-se em um segundo ponto de diálogo entre Maria Isaura e Roger Bastide: o etnocentrismo, problema central nas ciências sociais e humanas. Segundo Maria Isaura, a perspectiva "antietnocêntrica" de Bastide "consistia em aproveitar as contribuições dos nacionais, cujas conclusões, consideradas problemas a serem verificados, constituíam ponto de partida para outras pesquisas" (Pereira de Queiroz, 1983, p. 13). Bastide foi ainda mais longe. Defendeu o conhecimento dos "nativos" como o verdadeiro, considerando o subjetivismo e a intuição como fontes válidas de conhecimento, o que poderia levar à conversão do sujeito do conhecimento ao objeto da investigação como um pressuposto metodológico (Moraes, 1986, p. 105). Se Maria Isaura foi intransigente com a perspectiva etnocêntrica nas ciências sociais, o mesmo não aconteceu com a aceitação do 66 subjetivismo ou da intuição no trabalho de pesquisa. Rigorosa nesse sentido, diferenciou-se não somente de Roger Bastide, como de Gilberto Freyre e seu método empático e introspectivo (Villas Bôas, 2006). Na advertência aos artigos reunidos em Cultura, sociedade rural e sociedade urbana no Brasil, nomeia os postulados que sempre a conduziram na pesquisa, sublinhando que "são os dados empíricos que atraem sem exceção nossa observação e reflexão; e mesmo quando o raciocínio aborda considerações teóricas, é sempre a partir dos dados empíricos, e visando sua compreensão" (Pereira de Queiroz, 1978, p. X) ${ }^{8}$.

É curioso observar, contudo, que Maria Isaura marca sua posição, no que respeita ao etnocentrismo, de outro

\footnotetext{
${ }^{7}$ Quanto à permanência de ideias de Oliveira Vianna na sociologia política, inclusive de Maria Isaura, ver Botelho (2007).

${ }^{8}$ É possível que a posição intransigente de Maria Isaura tenha sofrido alterações em um de seus últimos livros, Carnaval brasileiro. O mito e o vivido (Pereira de Queiroz, 1992).
} 
modo, ao recusar a noção evolucionista do tempo histórico. Ela rechaça a visão evolucionista e teleológica da história como etnocêntrica, apropriando-se de uma noção de tempo que contempla concomitantemente o processo universal civilizatório padronizador em tensão constante com as singularidades históricas e culturais dos grupos humanos, locus privilegiado da liberdade humana, segundo a socióloga. Essa maneira própria de posicionar-se contra o etnocentrismo a conduziu na busca da pluralidade dos fenômenos na sociedade brasileira.

Se o interesse pela cultura está presente nas obras dos dois autores, ele se realiza de modo bem diverso em cada uma delas. Poderia este ser um terceiro ponto a mostrar as proximidades e as diferenças entre Maria Isaura e Bastide. Bastide está interessado na arte e na literatura, na interpenetração das culturas, nas religiões de origem africana com o intento de compreender peculiaridades da cultura brasileira. Ao indagar em suas investigações como foi possível a integração de culturas de origem tão diferentes, alcança formular o princípio da cisão ${ }^{9}$ que não apenas possibilitava argumentar contra as visões dualistas da sociedade brasileira, como permitia compreender que grupos e indivíduos diversos conservassem sua cultura própria e convivessem com a cultura do outro (Pereira de Queiroz, 1983, pp. 31-7).

Maria Isaura não pretendia estudar a cultura brasileira a partir de suas origens raciais e étnicas, questionando a lógica de sua integração. $\mathrm{O}$ enigma da cultura brasileira

\footnotetext{
${ }^{9}$ A formulação desse conceito de Bastide partiu de suas observações e estudos das religiões afro-brasileiras e do conceito de participação de Lévi-Bruhl. Considerava ele que as coletividades negras se pautavam por dois diferentes sistemas de interpretação do universo: ora seguiam os valores de sua cultura, ora os valores da cultura ocidental branca. Em um primeiro momento, utilizou-se do conceito de participação de Lévi-Bruhl, para quem o pensamento primitivo era destituído da necessidade de afirmar um termo quando se nega outro, possibilitando a ligação das coisas e dos seres. No entanto, Bastide vai mais longe em suas investigações ao perceber a coexistência de duas orientações culturais distintas que, embora separadas, não se encontram em oposição. Ver Pereira de Queiroz (1983 pp. 27-37).
} 
sempre esteve no seu horizonte de expectativas intelectuais. Mas não ousou enfrentá-lo. Investida dos ensinamentos de Émile Durheim e Georges Gurvitch, era a sociedade em seus múltiplos planos e em movimento no tempo que norteava suas pesquisas sobre a cultura.

Este social que vem aguçando há mais de vinte anos a nossa curiosidade, não o vemos nem imóvel nem homogêneo; está partilhado em argumentos variados que ora se apresentam como grupos, ora como coletividades, ora como parentelas, ora como classes sociais - segmentos que compõem uma dada estrutura na qual se distribuem segundo determinados critérios de estratificação. Sem analisar a composição das estruturas e das estratificações, não alcançamos uma compreensão da sociedade global (Pereira de Queiroz, 1978, p. X).

O prefácio de Roger Bastide ao livro $O$ messianismo no 68 Brasil e no mundo (Pereira de Queiroz, 1976b [1965]) é esclarecedor da posição de Maria Isaura e das diferenças entre ambos no tocante a aspectos do estudo da cultura relacionados à religião. Embora destaque que a descoberta mais importante de Maria Isaura na pesquisa sobre os movimentos messiânicos seja a relação que a pesquisadora estabelece entre as sociedades de linhagens, parentelas e de famílias extensas com o desenrolar daqueles movimentos, Bastide lamenta que a "modéstia demasiada" da autora a tenha impedido de apontar adequadamente sua descoberta - deixando-a aparecer apenas no final do livro, sobretudo porque, a partir daquela descoberta, Maria Isaura se posicionava contra o reconhecimento de movimentos políticos de sua contemporaneidade como formas secularizadas de "messianismos" e contra os estudos que buscavam arquétipos religiosos inscritos sob o anarquismo ou o comunismo à maneira de Mircea Eliade. Contudo, fiel às suas perspectivas cognitivas, Bastide sublinha e discute a ausência de aná- 
lise da dimensão do sagrado dos movimentos messiânicos. Lamenta que Maria Isaura tenha "abandonado" o sagrado para procurar as sociedades que se escondiam atrás dos diferentes tipos de movimentos messiânicos, investigando sua dinâmica social (cf. Bastide, 1976, pp. XV-XXII).

Um estudo rigoroso demonstraria, talvez, que foram poucas as afinidades intelectuais de Roger Bastide e Maria Isaura. Se ela não era, de fato, "herdeira" das orientações teóricas de seu ex-professor, contrariando posições teóricas e metodológicas assumidas por ele, ainda que sem polemizar, os motivos do seu engajamento na construção da memória do mestre francês ficam ainda mais obscuros. Suspeito, no entanto, que ela e Roger Bastide compartilharam valores relevantes na vida intelectual - a liberdade, a crítica e a autonomia intelectual. O projeto de construção da memória de Bastide estaria voltado para esses valores em detrimento da paixão e do cálculo? Ou teria como propósito contribuir para uma história das ciências sociais brasileiras? Sabe-se que as ciências carregam consigo uma história rica e complexa, elaborada de perspectivas diversas que, entretanto, contam sempre, de uma forma ou de outra, com nomes, assinaturas e autores.

\section{Projeto inacabado}

Um ano após a morte de Roger Bastide, em 1974, Maria Isaura Pereira de Queiroz escreveu a Jeanne Bastide, viúva de seu colega e amigo, desculpando-se pelo atraso no envio de prefácio para a publicação, na França, de Arte e sociedade.

Apressei-me em terminar o prefácio de Arte e sociedade para lhe enviar juntamente com algumas notícias que tenho para lhe dar. Entretanto, desde a semana passada os acontecimentos de ordem política transtornaram minha rotina, e não poderei terminar definitivamente o prefácio nos próximos quinze dias [...] 
Para ser mais precisa: um professor da Escola de Comunicações e Artes da USP, jornalista da TV Cultura (que pertence ao Estado) e do Jornal da Tarde (que pertence a $O$ Estado de S. Paulo) foi preso e morto sob tortura. A escalada de prisões foi retomada depois de alguns meses, e fez recrudescer, nesses últimos vinte dias, protestos de diferentes instituições profissionais e da Igreja, mas sem resultado. A morte de nosso colega, que não resistiu aos choques elétricos, deu naturalmente outra dimensão aos protestos, e criou na USP, e no meio universitário paulista em geral, um clima de agitação, mas também uma reação sadia de protesto que não se via mais desde 1968-1969. Certamente tudo isso toma tempo e não deixa a cabeça calma para avaliar se aquilo que se escreve tem valor ou não. Espero, portanto, lhe enviar o prefácio dentro de vinte dias (Carta de Maria de Isaura a Mme. Jeanne Bastide, São Paulo, 31 out. 1975, Imec - tradução livre) ${ }^{10}$.

As cartas de Maria Isaura à viúva Jeanne Bastide e à sua filha, Suzanne, são entremeadas de notícias do dia a dia político e econômico no Brasil, que revelam aspectos da vida da intelectualidade brasileira na segunda metade da década de 1970. Maria Isaura começa a formular o projeto de publicação das obras completas de Roger Bastide em novembro de 1976, com o apoio de Manuel Diégues Júnior, diretor do Departamento de Assuntos Culturais do Ministério da Cultura e membro do Conselho Nacional de Cultura. Diégues ficou interessado na iniciativa conjunta do Centro de Estudos Rurais e Urbanos (Ceru), que Maria Isaura criara e dirigia, e do Instituto de Estudos Brasileiros (IEB), dirigido por José Aderaldo Castelo. Ela pretendia reunir os artigos esparsos de Roger Bastide em diversos volumes, a

\footnotetext{
${ }^{10}$ Maria Isaura refere-se ao assassinato do jornalista Vladimir Herzog, em 1975, nas dependências do Segundo Exército, em São Paulo.
} 
começar com os artigos publicados no Brasil, uma vez que estavam traduzidos, e depois os artigos publicados em francês, de tal forma que pudessem integrar uma coleção de "Obras completas" à qual daria o nome de Bastidiana. Mais adiante, decide dividir as obras completas em dois volumes, sobre arte e literatura, e sobre problemas de interpenetração de civilizações e folclore.

“O projeto se desenvolverá lentamente”, dizia ela à viúva e à filha de Bastide, em 1977, "e quando conseguirmos - o dinheiro", voltaria a pedir a permissão das duas para a publicação. Reclamando das condições de trabalho tensas e difíceis devido à situação política do país, informa madame Bastide sobre o desdobramento do projeto em duas diferentes realizações: (1) o Arquivo Roger Bastide no IEB/USP, cujo acervo contaria com microfilmes e cópias de artigos de jornais de autoria de Bastide, assim como de artigos sobre Bastide; (2) as "Obras completas", que incluiriam a datilografia dos textos, a revisão de ortografia, a tradução dos textos em francês, a correção das traduções existentes. Advertia que esse seria um trabalho de equipe grande e custoso, e duraria pelo menos um ano. Somente depois viria a publicação.

Maria Isaura consegue o apoio financeiro do Ministério da Cultura para o projeto da publicação das obras completas. Seleciona artigos e faz as traduções necessárias. Reconhece o apoio inestimável de Charles Beylier. Porém, o dinheiro é pouco para a publicação. Em carta datada de 28 de janeiro de 1978, escreve a Suzanne Bastide sobre o contrato para publicação das obras completas pela Companhia Editora Nacional. Ambas estranham uma das cláusulas contratuais que dava direito à editora de fazer a revisão final de forma e conteúdo do manuscrito, assim como a revisão das cópias tipográficas. Maria Isaura atribui à censura o direito da revisão final pela editora: "o governo se dá o direito de riscar as partes de obras que julgar inconvenientes para publicação" ["le gouvernement se donne le droit 
de rayer les parties de l'ouvrage qu'il ne lui conviendra pas de publier"]. Prefere ignorar o contrato, explicando que possivelmente a cláusula "inusitada" se devia ao fato de a editora ter sido adquirida pelo Banco do Brasil. No mesmo ano, os arquivos de Roger Bastide organizados por Charles Beylier são definitivamente incorporados ao IEB/USP.

As cartas vão se distanciando umas das outras. A "inflação galopante”, a insuficiência dos recursos para a datilografia e tradução dos textos para as obras completas retardam o projeto. Em 1980, Maria Isaura faz um balanço das diversas atividades em prol da memória de Roger Bastide, incluindo publicações nos Cadernos do CERU, na revista Ciência e Cultura, a coletânea sobre Roger Bastide, a ser publicada na coleção Grandes Cientistas Sociais, coordenada por Florestan Fernandes, além de seminários e homenagens ao professor francês. Suas visitas à viúva e Suzanne Bastide, em Paris, vão se tornando raras. Em carta de 21 de janeiro de 72 1989, desculpa-se com Suzanne por não tê-la encontrado; estava em Roma e havia passado um fim de semana muito agitado em Paris. Diz que a crise econômica e política no Brasil provocava uma espécie de "chaos extremement inquietant". Era preciso avaliar a continuidade do projeto ("la collection qu'on voulait faire"). Ela se encarregaria de escrever assim que a situação melhorasse. O tempo, que abrira "claros irreparáveis" entre Roger Bastide e os amigos brasileiros, conforme escrevera Maria Isaura, referindo-se à última viagem de Bastide ao Brasil, em 1974, aos poucos a afastava também da família de seu professor.

As cartas não revelam os motivos que levaram Maria Isaura a se ocupar, entre outros projetos, daquele da memória de seu amigo. Confirmam a existência efetiva do projeto através da sequência de realizações planejadas e bem-sucedidas, sem deixar de apontar as condições desfavoráveis e limitadas de seu desenvolvimento - da falta de dinheiro às questões políticas e econômicas - que, de resto, 
são próprias do desenrolar de inúmeros projetos e, aparentemente, impediram a publicação das obras completas de Bastide em português.

No momento em que prevalece a "cultura da memória", na acepção de Andreas Huyssen ${ }^{11}$, sabe-se muito bem que a memória é fonte de recursos para a construção do futuro. Selecionar, agrupar, guardar os textos de um autor é preservar a possibilidade de sua nova interpretação e exegese; é reunir o autor com outros autores, como demonstra Maria Isaura ao dizer a madame Bastide que os arquivos do marido seriam depositados no IEB ao lado dos "Arquivos de Mario de Andrade" e dos "Arquivos de Fernando de Azevedo" (Carta de 7 ago. 1977). O projeto de Maria Isaura contribui certamente para a história das ciências sociais, sua identidade cognitiva e histórica e seu futuro imprevisível. Contudo, podemos ainda indagar de que maneira o projeto descortina características da individualidade de sua autora. Ao construir a memória de Bastide, atentando para as suas ideias, e não para documentos de sua história de vida, Maria Isaura fala de si por meio do compartilhamento de uma experiência na qual a pesquisa, hipóteses e questões de trabalho orientadas para o conhecimento da sociedade brasileira foram, possivelmente, os temas centrais de seu diálogo e amizade.

\section{Glaucia Villas Bôas}

é professora do Departamento de Sociologia e do Programa de Pós-Graduação em Sociologia e Antropologia da UFRJ e pesquisadora da Faperj e do CNPq.

\footnotetext{
${ }^{11}$ Para Andreas Huyssen (2000, pp. 9-40), um dos fenômenos políticos e culturais mais surpreendentes nos últimos anos foi a centralidade que a memória adquiriu nas sociedades ocidentais, deslocando o privilégio que o futuro teve na constituição da modernidade. A cultura da memória define-se por um deslocamento na experiência e na sensibilidade do tempo, que se explica pelas transformações históricas, políticas e tecnológicas das últimas décadas. Argumenta, entretanto, que é preciso distinguir "os passados usáveis dos passados dispensáveis" e verificar seus vínculos com o futuro.
} 


\section{Bibliografia}

BASTIDE, R. 1976. O messianismo no Brasil e no mundo. 2. ed. São Paulo: Alfa-Omega.

BOTELHO, A. 2007. "Sequências de uma sociologia política brasileira". Dados, v. 50, n. 1, pp. 49-82.

BOTELHO, A.; CARVALHO, L. C. 2011. "A sociedade em movimento: dimensões da mudança na sociologia de Maria Isaura Pereira de Queiroz”. Sociedade e Estado, v. 26, n. 2, pp. 209-38.

BRAGA, M. L. S. 2000. "A recepção do pensamento de Roger Bastide no Brasil”. Sociedade e Estado, v. 15, n. 2, pp. 331-60. . 2009. "Entre o claro e o escuro: Roger Bastide e Claude LéviStrauss”. ComCiência, Campinas, n. 108.

FRY, P. 1986. "Gallus africanus est, ou como Roger Bastide se tornou africano no Brasil”. In: SIMSON, O. (org.). Revisitando a terra de contrastes: a atualidade da obra de Roger Bastide. São Paulo:

FFLCH/Ceru.

HUYSSEN, A. 2000. Seduzidos pela memória. Rio de Janeiro: Aeroplano.

LOPES, A. M. 2012. Vida rural e mudança social no Brasil: tradição e modernidade na sociologia de Maria Isaura Pereira de Queiroz. Tese de doutorado. Programa de Pós-Graduação em Sociologia e Antropologia da Universidade Federal do Rio de Janeiro.

MORAES, E. J. 1986. "O idêntico e o diferente. Leitura de Roger Bastide”. In: SIMSON, O. (org.). Revisitando a terra de contrastes: a atualidade da obra de Roger Bastide. São Paulo: FFLCH/Ceru.

MORAES Filho, E. (org.). 1993. Simmel: Sociologia. São Paulo: Ática. (coleção Grandes Cientistas Sociais).

PEIXOTO, F. A. 2000. Diálogos brasileiros. Uma análise da obra de Roger Bastide. São Paulo: Edusp.

PEREIRA DE QUEIROZ, M. I. 1957. “La 'Guerre Sainte’ au Brésil: le mouvement messianique du 'Contestado'”. Boletim FFLCH/USP, São Paulo, n. 187, Sociologia I, 5. . 1973. O campesinato brasileiro: ensaios sobre civilização e grupos rústicos no Brasil. Petrópolis: Vozes. 1976a. O mandonismo local na vida política brasileira e outros ensaios.

São Paulo: Alfa-Ômega. 1976b [1965]. O messianismo no Brasil e no mundo. 2. ed. São Paulo: Alfa-Ômega. 1976c. "Roger Bastide e o Brasil". Afro-Ásia, n. 12, pp. 47-52. . 1978. Cultura, sociedade rural e sociedade urbana no Brasil. São Paulo: Livros Técnicos e Científicos/Edusp. 
1979. Brésil, XIXe. siècle: les précurseurs des sciences sociales. In:

Culture, science et développement (Mélanges en l'honneur de Charles Morazê).

Toulouse: Privat.

1983. Nostalgia do outro e do alhures: a obra sociológica de Roger

Bastide. In: PEREIRA DE QUEIROZ, M. I. P. (org.). Roger Bastide. São

Paulo: Ática. (coleção Grandes Cientistas Sociais). 1990. Discurso de agradecimento proferido na cerimônia

de outorga do título de professora Emérita do Departamento de

Sociologia da Faculdade de Filosofia, Letras e Ciências Humanas da

USP, 31 maio.

1992. Carnaval brasileiro. O mito e o vivido. Rio de Janeiro:

Brasiliense.

ROTH, G. 1995. "Marianne Weber y su círculo". In: WEBER, M. Biografía de Max Weber. México: Fondo de Cultura Económica. pp. 11-55.

SIMSON, O. (org.). 1986. Revisitando a terra de contrastes: a atualidade da obra de Roger Bastide. São Paulo: FFLCH/Ceru.

VILLAS BÔAS, G. 2006. Mudança provocada. Rio de Janeiro: Topbooks. 2009. "A tradição renovada na obra de Maria Isaura Pereira de

Queiroz”. In: BOTELHO, A.; SCHWARCZ, L. M. (orgs.). Um enigma chamado Brasil. São Paulo: Companhia das Letras. pp. 262-85.

2010. "Para ler a sociologia política de Maria Isaura Pereira de

Queiroz”. Estudos Políticos, n. 1, pp. 37-44. 


\section{AMIZADE E MEMÓRIA: MARIA ISAURA PEREIRA DE QUEIROZ E ROGER BASTIDE}

GLAUCIA VILLAS BÔAS

Resumo: $\mathrm{O}$ artigo examina os motivos que levaram Maria Isaura Pereira de Queiroz a envolver-se com um projeto de memória, voltado para a preservação e publicação das obras completas de seu mestre e amigo Roger Bastide, professor da Universidade de São Paulo entre 1938 e 1954, morto em 1974. A correspondência de Maria Isaura à viúva e à filha de Bastide, datada de 1975 a 1989, evidencia os esforços empreendidos pela socióloga, assim como as adversidades políticas e financeiras que enfrentou para a realização do projeto que não logrou concluir.

Palavras-chave: Memória; Ciências Sociais; Maria Isaura Pereira de Queiroz; Roger Bastide.

\section{FRIENDSHIP AND MEMORY: MARIA ISAURA PEREIRA DE QUEIROZ AND ROGER BASTIDE}

Abstract: The article examines the reasons that motivated Maria Isaura Pereira de Queiroz to become involved with the memory project aimed at the preservation and publication of the complete works of her master and friend Roger Bastide, professor at the University of São Paulo from 1938 to 1954, who died in 1974. Maria Isaura's letters to Bastide's widow and daughter written from 1975 to 1989 reveal the efforts undertaken by her as well as the difficulties she faced carrying out a project that remained unfinished.

Keywords: Memory; Social Sciences; Maria Isaura Pereira de Queiroz; Roger Bastide. 